\title{
LOCAL BEHAVIOUR OF THE DERIVATIVE OF A MID POINT CUBIC SPLINE INTERPOLATOR
}

\author{
H.P. DIKSHIT and S.S. RANA \\ Department of Mathematics and Computer Sciences \\ R.D. University \\ Jabalpur 482001 India
}

(Received January 16, 1985 and in revised form June 5, 1985)

ABSTRACT. In the present paper, we obtain an asymptotically precise estimate for the derivative of the difference between the cubic spline interpolating at the mid points of a uniform partition and the function interpolated.

KEY WORDS AND PHRASES. Local behaviour, derivative, mid point, cubic spline interpolation.

1980 MATHEMATICS SUBJECT CLASSIFICATION CODE. Primary 41 A05, 65 DO7

1. INTRODUCTION.

Consider a partition $P$ of $[0,1]$ defined by

$$
\mathrm{P}: 0=\mathrm{x}_{0}<\mathrm{x}_{1}<\ldots<\mathrm{x}_{\mathrm{n}}=1
$$

such that $x_{i}-x_{i-1}=p$ for all $i$. Let $P_{3}$ be the class of all piecewise polynomial functions $s$ defined over $P$ such that the restriction $s_{1}$ of $s$ over $\left[x_{1-1}, x_{1}\right]$ is a polynomial of degree 3 or less for $i=1,2, \ldots, n$. The class of periodic cubic splines over $P$ is defined by

$$
S(3, P)=\left\{s: s \in P_{3}, s \in C^{2}[0,1], s^{(j)}(0)=s^{(j)}(1), j=0,1,2\right\} \text {. }
$$

Under certain restrictions on the choice of $y$, Mehr and Sharma [1] have studied convergence properties of the interpolant from $S(3, P)$ matching a given function at the points $y_{i}=x_{i-1}+y p(0 \leqq y \leqq 1), i=1,2, \ldots, n$. However, the interpolation at the mid points, which corresponds to the choice $y=1 / 2$ is not covered in [1]. Assuming to a nonnegative measure $d g$, where $g(x+p)-g(x)=K$ (constant), one of the authors (Dikshit [2], Theorem 2) has proved the following which covers the case $y=1 / 2$.

THEOREM 1. Suppose $\mathrm{n}$ is odd and

$$
\int_{0}^{\mathrm{p}}\left(6 \mathrm{p} \mathrm{x}^{2}-4 \mathrm{x}^{3}-\mathrm{p}^{3}\right) \mathrm{dg}=0, \int_{0}^{\mathrm{p}} \mathrm{dg}>0 .
$$

Then there exists a unique $s \in S(3, P)$, which satisfies the interpolatory condition:

$$
\int_{x_{i-1}}^{x_{i}}(f(x)-s(x)) d g=0, i=1,2, \ldots, n .
$$

We observe that the case in which $g$ has a single jump of 1 at $\mathrm{p} / 2$, (1.1) holds and the interpolatory condition (1.2) reduces to the condition:

$$
s\left(t_{i}\right)=f\left(t_{i}\right): t_{i}=\left(x_{i}+x_{i-1}\right) / 2, i=1, \ldots, n .
$$


It may be mentioned that the derivative of a cubic spline interpolator has been used for smoothing of histograms (see Boneva, Kendall and Stefanov [3] and Schoenberg [4]). Considering a function $f \in C^{4}$ and its unique spline interpolant $s \in S(3, P)$ matching at the knots : $\left\langle x_{i}>_{i=0}^{n}\right.$, Rosenblatt [5] has obtained asymptotically precise estimate for $s^{\prime}-f^{\prime}$. In the present paper, we obtain a similar precise estimate for the cubic spline interpolating at the mid points between the successive knots.

2. ERROR BOUNDS.

Let $\mathrm{f} \varepsilon \mathrm{C}^{4}$ and be periodic with period 1. Let the number of mesh points of $P$ be even. In this section, we shall estimate $(s-f)^{\prime}$ where $s$ is the cubic spline satisfying the interpolatory condition (1.3). Let $M$ and $F$ denote the transpose of $\left[M_{1}, M_{2}, \ldots \ldots ., M_{n-1}\right]$ and $\left[F_{1}, F_{2}, \ldots \ldots ., F_{n-1}\right]$ respectively, with $M_{1}=s^{\prime \prime}\left(x_{1}\right)$ and

$$
F_{i}=12 p^{-2}\left(\sum_{j=1}^{i}-j=\sum_{i+1}^{n}\right)(-1)^{i+j} \alpha_{j}
$$

where $\alpha_{j}=f\left(t_{j+1}\right)-2 f\left(t_{j}\right)+f\left(t_{j-1}\right)$. For convenience, we consider in the rest of this section, the class $S *(3, P)$ of splines $s \in S(3, P)$ for which $s^{\prime \prime}(0)=0$. Thus it follows from the proof of Theorem 1 that

$$
\mathrm{C} M=\mathrm{F}
$$

where $n-1 \times n-1$ coefficient matrix $c=\left(c_{i j}\right)$ is given by

$$
2 c_{i j}=\delta_{i-1 j}+22 \delta_{i j}+\delta_{i+1 j}
$$

In order to estimate $e^{\prime}$, we first determine an upper bound for $e^{\prime \prime}\left(x_{1}\right)$. For this we notice that the equation (2.2) yields

$$
C E=F^{\prime \prime}
$$

where $E$ and $F^{\prime \prime}$ are the transpose of the matrices $\left[E_{1}, E_{2}, \ldots, E_{n-1}\right]$ and $\left[F_{1}^{\prime \prime}, F_{2}^{\prime \prime}, \ldots \ldots \ldots \ldots, F_{n-1}^{\prime \prime}\right]$ respectively, with $E_{i}=e^{\prime \prime}\left(x_{i}\right)$ and

$$
F_{1}^{\prime \prime}=F_{i}-\beta_{i}
$$

where $2 B_{i}=f^{\prime \prime}\left(x_{i-1}\right)+22 f^{\prime \prime}\left(x_{i}\right)+f^{\prime \prime}\left(x_{i+1}\right)$.

$C$ is of course invertible (see [2], p. 108) and we first obtain the following preliminary results for determining the elements of $\mathrm{C}^{-1}$.

LEMMA 2.1. For given real numbers $a$ and $b$ with $b \geqq a$, let $D_{n}(a, b)=\left(d_{1 j}\right)$ be $a n \times n$ matrix with

$$
d_{i j}=(1-a) \delta_{i-1 j}+2 b \delta_{i j}+a \delta_{i+1 j}
$$

and $\beta=\left(b^{2}-a+a^{2}\right)^{\frac{1}{2}}$. Then

$$
2 \beta\left|D_{n}(a, b)\right|=(b+\beta)^{n+1}-(b-\beta)^{n+1}
$$

Proof of Lemma 2.1. It is easily seen that $\left|D_{n}(a, b)\right|$ satisfies the difference equation:

$$
\left|D_{n}(a, b)\right|-2 b\left|D_{n-1}(a, b)\right|+a(1-a)\left|D_{n-2}(a, b)\right|=0 \text {, }
$$

with $\left|D_{-1}(a, b)\right|=0,\left|D_{0}(a, b)\right|=1,\left|D_{1}(a, b)\right|=2$ b. The lemma follows from the 
above difference equation by using the induction hypothesis.

LEMMA 2.2. Suppose $b \geqq 1 / 2$ and $Q_{n}(\alpha, b)$ is the matrix obtained from $D_{n}(1 / 2, b)$ by replacing $1 / 2$ by $\alpha$ in its first row. Then

$$
q^{-n}(2 b+r)\left|Q_{n}(\alpha, b)\right|=2 b\left(1-r^{2 n}\right)+\alpha r\left(1-r^{2 n-2}\right)
$$

where $r=(-1 / 2 q)=-2\left(b-\left(b^{2}-1 / 4\right)^{\frac{1}{2}}\right)$.

Proof of Lemma 2.2. It follows from the definition of $Q_{n}(\alpha, b)$ that

$$
2\left|Q_{n}(\alpha, b)\right|=4 b\left|D_{n-1}(1 / 2, b)\right|-\alpha\left|D_{n-2}(1 / 2, b)\right|
$$

with $\left|Q_{0}(\alpha, b)\right|=1$ and $\left|Q_{1}(\alpha, b)\right|=2 b$. The result of Lemma 2.2 follows from (2.8) by an application of Lemma 2.1 .

LEMMA 2.3. The coefficient matrix of (2.2) is invertible and if $C^{-1}=\left(\theta_{1 j}\right)$, then $\theta_{i j}$ can just be approximated asymptotically as $n \rightarrow \infty$ by

$$
2 r^{|j-i|}(22+r)
$$

where $0<\varepsilon<\mathrm{i} / \mathrm{n}, \mathrm{j} / \mathrm{n}<1-\varepsilon$ and $\mathrm{r}=2 \sqrt{30}-11$.

REMARK 2.1. It is interesting to note that the estimate (2.9) is sharper than that obtained in terms of the infimum of the excess of the positive value of the leading diagonal elements over the sum of the positive values of other elements in each row. For, adopting the latter approach, we see from (2.2) that $\left\|C^{-1}\right\| \leqq 0.1$ whereas (2.9) together with the fact that

$$
\sum_{i} \frac{2}{22+r} r^{|j-i|}=\frac{2(1+r)}{(1-r)(22+r)}
$$

shows that the $\left\|C^{-1}\right\|$ does not exceed 0.084 .

Proof of Lemma 2.3. Taking $2 b=11$ and $\alpha=1 / 2$ in $Q_{n}(\alpha, b)$, observe that the coefficient matrix $C$ satisifes the following difference equation

$$
4|\mathrm{C}|=44\left|Q_{n-2}(1 / 2,11 / 2)\right|-\left|Q_{n-3}(1 / 2,11 / 2)\right| \text {. }
$$

Thus, it follows from Lemma 2.2 that

$$
(11+r) q^{-n+2}|c|=(11+r / 2)^{2}-r^{2 n-6}(11 r+1 / 2)^{2} .
$$

In order to estimate $C^{-1}=\left(\theta_{i j}\right)$, we obtain the elements $\theta_{i j}$ from the cofactors of the transpose matrix. Thus, for $0<i \leqq j \leqq n-2$ or $i=j=0$ (confer Ahlberg, et al. [6], pp. 35-38)

$$
\begin{aligned}
& |c| \theta_{i j}=(q r)^{j-1} Q_{i}(1 / 2,11 / 2) Q_{n-2-j}(1 / 2,11 / 2) \text { and for } 0<j \leqq n-2, \\
& |c| \theta_{o j}=(q r)^{j} Q_{n-2-j}(1 / 2,11 / 2) .
\end{aligned}
$$

Thus, using the result of Lemma 2.2 and (2.10), we observe that for $0<1 \leq j \leq n-2$,

$$
\begin{aligned}
& (11+r)\left(1-r^{2 n}\right) \theta_{i j}=r^{j-i}\left(1-r^{2 i+2}\right)\left(1-r^{2 n-2 j-2}\right), \\
& (11+r / 2)\left(1-r^{2 n}\right) \theta_{i n-2}=r^{n-2-i}\left(1-r^{2 i+2}\right) \text {, for } 0 \leqq i \leqq n-2, \\
& (11+r / 2)\left(1-r^{2 n}\right) \theta_{o j}=r^{j}\left(1-r^{2 n-2-2 j}\right) \text {, for } 0<j<n-2, \\
& \text { and }(11+r / 2)^{2}\left(1-r^{2 n}\right) \theta_{o n-2}=r^{n-2}(11+r) \text {. }
\end{aligned}
$$


From the above expressions for $\theta_{i j}$, the result of Lemma 2.3 follows directly.

Since $C$ is invertible, it follows from the proof of Theorem 1 or more precisely from (2.3), that there exists a unique spline $s \in S^{*}(3, P)$ satisfying the interpolatory condition (1.3).

THEOREM 2.1. Let $s \in S^{*}(3, \mathrm{P})$ be the spline interpolant of a 1 - periodic function $f$ satisfying $(1.3)$. Let $\mathrm{f}^{(4)}$ exist and be a nonnegative monotonic continuous function, then for any fixed point $x$ such that $0<x<1$,

$$
\begin{aligned}
& s^{\prime}(x)-f^{\prime}(x)=f^{(4)} \quad(x)\left[\left(\left(t_{i+1}-x\right)^{4}-\left(t_{i}-x\right)^{4}\right) / p-p\left(\left(x_{i+1}-x\right)^{2}\right.\right. \\
& \left.\left.+10.08\left(x_{i}-x\right)^{2}+12.92\left(x-x_{i-1}\right)^{2}-13.92 p^{2}\right) / 4\right] / 24+o\left(p^{3}\right)
\end{aligned}
$$

as $\mathrm{n} \rightarrow \infty$.

Proof of Theorem 2.1. We first proceed to obtain the derivative $s^{\prime}$ of the mid point spline interpolant $s \in S *(3, P)$ of $f$. Considering the interval $\left[x_{i-1}, x_{i}\right]$, we observe that, since $s^{-}$is quadratic in the interval $\left[x_{i-1}, x_{i}\right]$

$$
2 p s^{\prime}(x)=-M_{i-1}\left(x_{i}-x\right)^{2}+M_{i}\left(x-x_{i-1}\right)^{2}+2 p C_{i}
$$

where the constants $C_{i}$ 's are to be determined by the requirement that $s \in C^{2}[0,1]$. Thus,

$$
M_{i} p=C_{i+1}-C_{i}
$$

and we have

$$
6 \mathrm{p} \mathrm{s}(\mathrm{x})=\mathrm{M}_{i-1}\left(\mathrm{x}_{i}-\mathrm{x}\right)^{3}+\mathrm{M}_{i}\left(\mathrm{x}-\mathrm{x}_{i-1}\right)^{3}+3 \mathrm{pc} \mathrm{c}_{i}\left(2 \mathrm{x}-\mathrm{x}_{i}-\mathrm{x}_{i-1}\right)+6 \mathrm{pb}_{i} .
$$

Again using the continuity requirement, we get

$$
p\left(c_{i}+c_{i+1}\right)=2\left(b_{i+1}-b_{i}\right) \text {. }
$$

Using (2.14) - (2.16) and the interpolatory condition (1.3), we have

$$
\begin{aligned}
48 s^{\prime}(x) & =M_{i-1}\left[p^{2}-24\left(x_{i}-x\right)^{2}\right]+24 M_{i}\left[\left(x-x_{i-1}\right)^{2}-p^{2}\right]-p^{2} M_{i+1} \\
& +48\left[f\left(t_{i+1}\right)-f\left(t_{i}\right)\right] .
\end{aligned}
$$

Thus, replacing $M_{i}$ by $e^{\prime \prime}\left(x_{i}\right)$ in $(2.17)$, we see that

$$
\begin{aligned}
48 \mathrm{p} \mathrm{s}^{\prime}(\mathrm{x}) & =\left[\mathrm{p}^{2}-24\left(\mathrm{x}_{i}-\mathrm{x}\right)^{2}\right] \mathrm{e}^{\prime \prime}\left(\mathrm{x}_{i-1}\right)+24\left[\left(\mathrm{x}-\mathrm{x}_{i-1}\right)^{2}-\mathrm{p}^{2}\right] \mathrm{e}^{\prime \prime}\left(\mathrm{x}_{i}\right) \\
& -p^{2} \mathrm{e}^{\prime \prime}\left(\mathrm{x}_{i+1}\right)+\mathrm{R}_{i}(\mathrm{f}),
\end{aligned}
$$

where $R_{i}(f)=\left[p^{2}-24\left(x_{i}-x\right)^{2}\right] f^{\prime \prime}\left(x_{i-1}\right)+24\left[\left(x-x_{i-1}\right)^{2}-p^{2}\right] f^{\prime \prime}\left(x_{i}\right)-p^{2} f^{\prime \prime}\left(x_{i+1}\right)$

$$
+48\left[f\left(t_{i+1}\right)-f\left(t_{i}\right)\right] \text {. }
$$

For convenience, we denote by $u_{j}$, appropriate points of $\left(x_{j-2}, x_{j+1}\right)$ which are not necessarily the same at each occurence. Thus by Taylor's Theorem, we have

$$
\begin{aligned}
R_{i}(f) / 48 p & =f^{-}(x)+f^{(4)}\left(u_{i}\right)\left[\left\{\left(t_{i+1}-x\right)^{4}-\left(t_{i}-x\right)^{4}\right\} / p-p\left\{\left(x_{i+1}-x\right)^{2}\right.\right. \\
& \left.\left.+24\left(x_{i}-x\right)^{2}-\left(x_{i-1}-x\right)^{2}\right\} / 4\right] / 24+o\left(p^{3}\right)
\end{aligned}
$$


Now writing $2 \beta_{i}=\left(\sum_{j=1}^{i}-\sum_{j=i+1}^{n}\right)(-1)^{i+j}\left(\beta_{j}+\beta_{j-1}\right)$, we have

$$
2 F_{i}^{\prime \prime}=\left(\sum_{j=1}^{i}-\sum_{j=i+1}^{n}\right)(-1)^{i+j}\left(24 p^{-2} \alpha_{j}-\beta_{j}-\beta_{j-1}\right)
$$

so that by 'Taylor's Theorem, we have

$$
F_{i}^{\prime \prime}=p^{2}\left(-\sum_{j=1}^{i}+\sum_{j=i+1}^{n}\right)(-1)^{i+j_{f}(4)}\left(u_{j}\right)+o\left(p^{2}\right) \text {. }
$$

Recalling the equation (2.3) and noticing that $C^{-1}=\left(\theta_{i j}\right)$, we have

$$
\begin{aligned}
\left(\mathrm{e}^{\prime \prime}\left(\mathrm{x}_{\mathrm{i}}\right)\right) & =\left(\left.\sum_{|\mathrm{R}-\mathrm{i}|}\right|_{\mathrm{m}} ^{+} \mid \sum_{|\mathrm{R}-\mathrm{i}|}<\mathrm{m}\right)\left(\theta_{\mathrm{iR}} \mathrm{F}_{\mathrm{R}}^{\prime \prime}\right) \\
& =\left(\mathrm{T}_{1}\right)+\left(\mathrm{T}_{2}\right)
\end{aligned}
$$

say, where $m$ is a sufficiently large positive integer. We shall estimate $T_{1}$ and $T_{2}$ separately. Suppose that $x$ is a fixed given point in $(0,1)$ and let $x_{1}=[n x] / n$ where $\mathrm{nx}$ denotes the largest integer not greater than $\mathrm{nx}$. Then it is clear that as $n \rightarrow \infty, i \cong x n$ and $n-i \cong(1-x) n$. Now using the monotonicity of $f^{(4)}$ and applying Abel's Lemma to the inner sums, we have for some positive constant $k_{1}$,

$$
\left|\left(\mathrm{T}_{1}\right)\right| \leq \mathrm{K}_{1}(0.29)^{\mathrm{m}} \mathrm{p}^{2}
$$

by virtue of Lemma 2.3 .

Next we see that for the values of $R$ occuring in $\mathrm{T}_{2}$,

$$
x_{R}-x=O(p)
$$

Thus, using the hypothesis that $\mathrm{f}^{(4)}$ is continuous and applying the result of Lemma 2.3 , we have

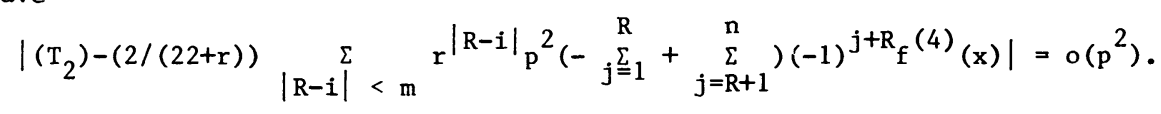

Combining the estimates of $\left(\mathrm{T}_{1}\right)$ and $\left(\mathrm{T}_{2}\right)$ and noticing that $\mathrm{m}$ is arbitrary, we complete the proof of Theorem 2.1 in view of $(2.18)$.

\section{REFERENCES}

1. MEIR, A. and SHARMA, A.. Convergence of a Class of Interpolatory Splines, J. Approx. Theory 1 (1968), 243-250.

2. DIKSHIT, H.P. On Cubic Interpolatory Splines, J. Approx. Theory 22 (1978), $105-110$.

3. BONEVA, L.I., KENDALL, D.G., and STEFANOV, I. Spline Transformations: Three New Diagnostic Aids for the Statistical Data Analyst, J. Royal Stat。 Soc. Ser. B 33 (1971), 1-70.

4. SCHOENBERG, I.J. Splines and Histograms in Spline Function and Approximation Theory Proceeding, Editors Meir, A. and Sharma, A. University of Alberta, Edmonton, 1972, ISNM 21 (1973), Birkhäuserverlag.

5. ROSENBLATT, M. The Local Behavior of the Derivative of Cubic Spline Interpolator, J. Approx. Theory 4 (1975), 382-387.

6. AHLBERG, J.H., NILSON, E.N., and WALSH, J.L. The Theory of Splines and Their Applications, Academic Press, New York, 1967. 


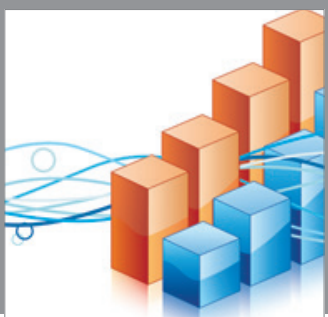

Advances in

Operations Research

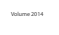

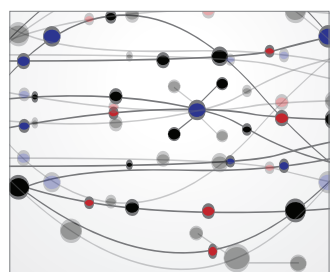

\section{The Scientific} World Journal
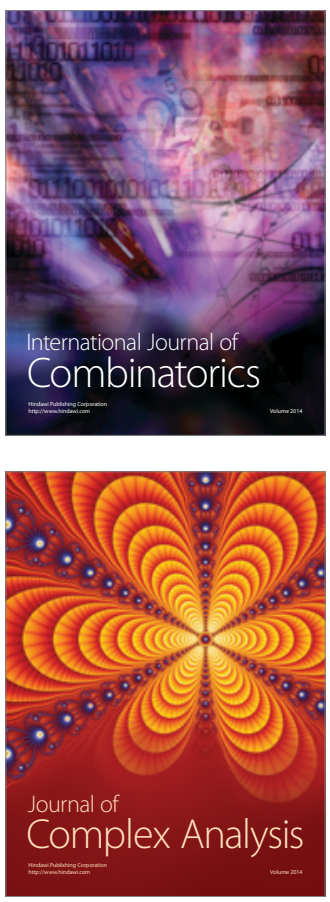

International Journal of

Mathematics and

Mathematical

Sciences
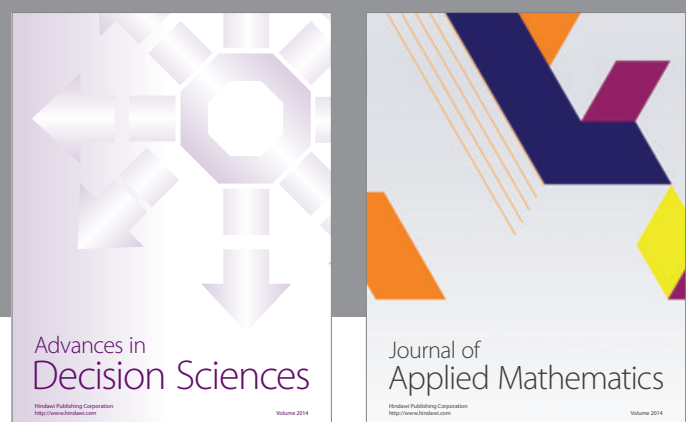

Journal of

Applied Mathematics
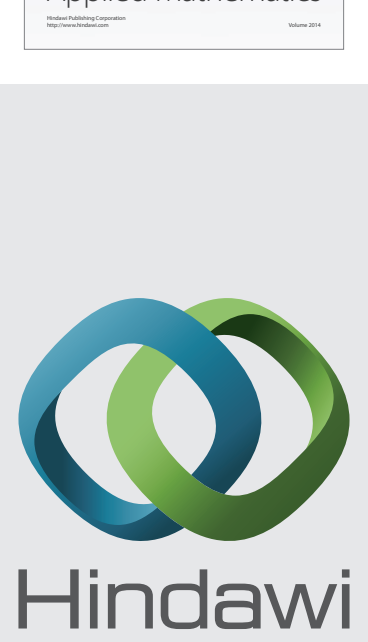

Submit your manuscripts at http://www.hindawi.com
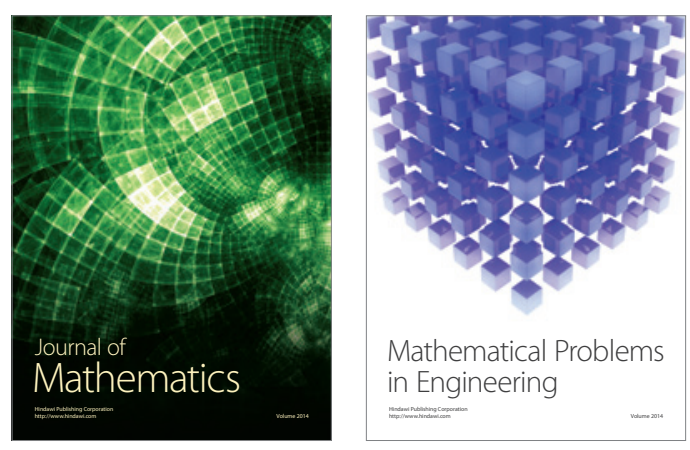

Mathematical Problems in Engineering
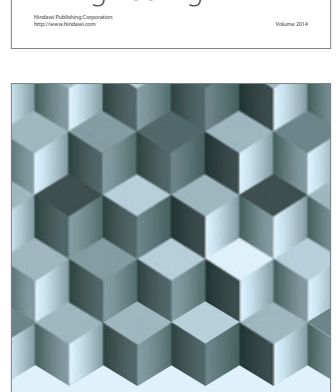

Journal of

Function Spaces
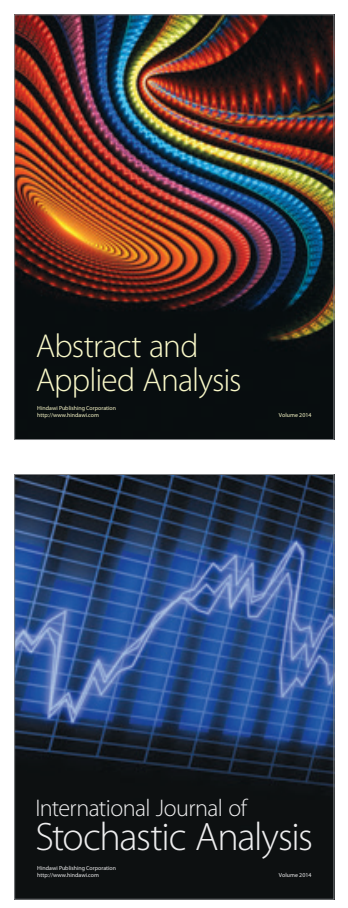

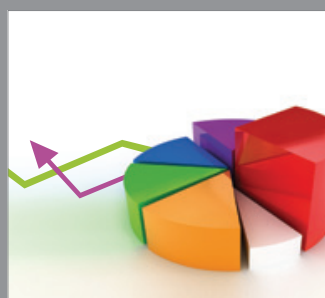

ournal of

Probability and Statistics

Promensencen
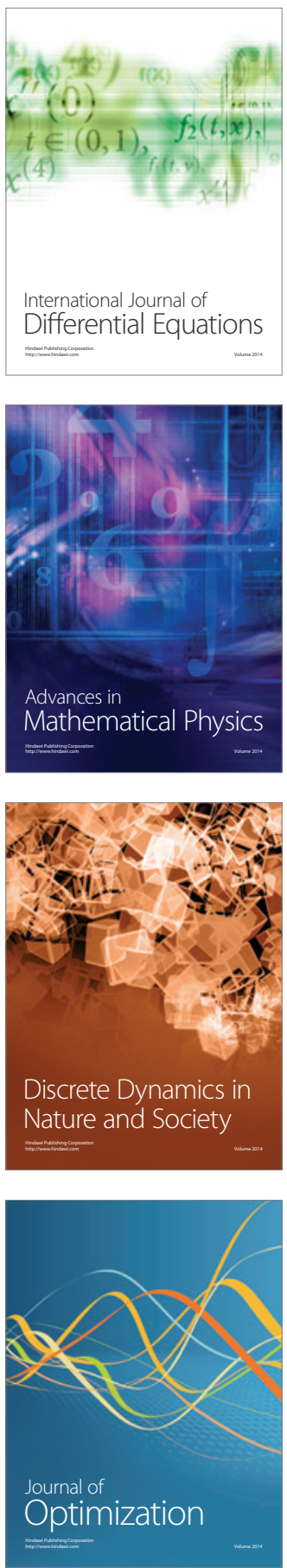